\title{
MASTER \\ MASTER
}

\section{FLUCTUATIONS IN LARGE-ANGLE $\pi \pm \mathrm{p}$ ELASTIC SCATTERING}

K. A. Jenkins, L, E, Price,

R. KLem, R, J. Miller, P. SChreiner,

H. Courant, Y. I. Makdisi, M. L. Marshak,

E. A. Peterson and K. Rumdick

PREPARED FOR

19th International Conference

August 23-30, 1978

TOKYO, JAPAN

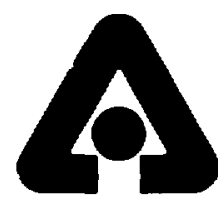

This repon was prepated as an account of wolk sponsored by the United States Govemment. Neithes the United Stales nor the Uniled Siates Depatment of

Energs. nor any of their employees, nut $2 \pi y$ of thetr

contractors, subentrsciors, or their employees. makes

any winzanty, express of implied, of assurtes any leal

lisbility or responsbisty for the scrurasy. Completeness

or usefulness of any information. appartutus, product or

process diselosed. or represents that its use would not

infringe ptivately owned rights. 
XIX International Conference on High Energy Physics Summary of Talk Presented in Session A1E

ANL-HEP-CP-78- 35

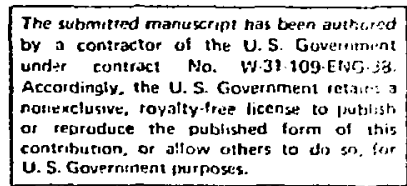

Fluctuations in Large-Angle $\pi^{\circ} p$ Elastic Scattering

K. A. JENKINS, L. E. PRICE

Columbia University, New York, NY 10027

R. KLEM, R. J. MILLER, P. SCHREINER

Argonne National Laboratory, Argonne, IL 60439

H. COURANT, Y. I. MAKDISI, M. L. MARSHAK,

E. A. PETERSON, K. RUDDICK

University of Minnesota, Minneapolis, MN 55455

Presented by P. Schreiner

An experiment has been performed at the Argonne Zero Gradient Synchratron to search systematically for fluctuations in $\pi^{+}$p scattering from 2 to $6.3 \mathrm{GeV} / \mathrm{c}$ and $\pi$ p scattering from 2 to $9.7 \mathrm{GeV} / \mathrm{c}$.

The experiment was motivated by Ericson ${ }^{(1)}$ and Frautschi ${ }^{(2)}$ who suggested that $\pi N$ resonances may continue to contribute to the $\pi^{ \pm} p \rightarrow \pi_{p}$ cross section at high momentum, but that they become so numerous that their effects overlap; Frautschi ${ }^{(2)}$ shows that there could be significant changes in $\sigma_{\text {el }}$ for $\Delta \mathrm{E}_{\mathrm{CM}} \approx \Gamma\left(\mathrm{N}^{*}\right)$, but the changes will come from variations in the number and properties of contributing resonances, rather than the effects of single resonance.

The apparatus and experimental method have been described previously. (3) However, we note here the characteristics of the experiment that are important to the search for fluctuations. Since there are no magnet apertures, the azimuthal acceptance is a smooth function of $\theta_{\mathrm{CM}}$ and is centered near $\theta_{\mathrm{CM}}=0.0$. The peak acceptance changes smoothly from 0.17 to 0.27 over the momentum range of the experiment. Thus narrow structure in the differential cross section cannot be introduced in dividing by the acceptance.

Data were taken in such a way that the momentum ranges of the 
beam overlapped for adjacent settings of the beam magnets. These overlapping bins provide an important test of the reproducibility of the data, since often the data at adjacent momentum settings were taken with the spectrometer arms at different angles and/or with weeks or months intervening. The absolute momentum calibration of the incident bea $n$ was measured to be $\pm 0.5 \%$.

The search for fluctuations has been conducted by plotting do/dt at fixed $t$ vs. s. Some of these graphs are shown in Fig. 1. Fixed $t$ cross sections have been chosen because of the known presence of structures in the cross section at fixed $t$, in particular a sharp dip at $t=-2.8(\mathrm{GeV} / \mathrm{c})^{2}$.

Lines have been drawn through the data points in Fig. 1 to guide the eye and to indicate the major structures that appear in the data. It is clear that the data cannot, in general, be represented by smooth curves and that significant, previously unknown structures with widths in s of $1-2 \mathrm{GeV}^{2} / \mathrm{c}^{2}$ are revealed. Plots at intermediate values of $t$ generally show a smooth transition between the graphs of Fig. 1.

We summarize here the characteristics of the observed structures: (a) Full widths are between 100 and $200 \mathrm{MeV}$ in CM energy. These widths are significantly narrower than the observed widths of established nucleon resonances, which for $\mathrm{s}>6 \mathrm{GeV}^{2} / \mathrm{c}^{2}$ are at least $350 \mathrm{MeV}$.

(b) None of the structures is present in all of the constant-t graphs. About half of the structures are centered at a constant value of $u$, but are present only for a limited range of $t$, even though there are data for the particular $u$ value in a wider range of $t$.

(c) The number and relative amplitude of the structures are qualitatively constant as a function of $s$ or $t$, and as a function of pion charge in the region where we have data for both $\pi^{+} p$ and $\pi^{-} p$. This behavior is in sharp contrast to similar plots of our pp elastic scattering data, where no significant narrow structure is observed, confirming the negative results of previous searches.

(d) Structures that appear in the same kinematic region for $\pi^{+} \mathbf{p}$ and $\pi$ - $p$ are not more prominent in $\pi^{+} p$ by a large factor (the scattering amplitude should be larger by a factor of 3) as they would be if due to pure $I=3 / 2$ states. 
The narrow widths and the relationship between $\pi^{+} p$ and $\pi^{-} p$ structures cannot be explained by known s-channel resonances. Thus it is probable that the structure is due to either new individual resonances or to multipleresonance fluctuations. In the latter case, the density of states must be different from the exponentially-rising mass spectrum of the statistical bootstrap model, since in that model Frautschi ${ }^{(2)}$ finds that the relative size of the structures must fall by about an order of magnitude across the region of $s$ measured by this experiment.

This work was partially supported by the U.S. Department of Energy.

\section{References}

1. T.E. O. Ericson, T. Mayer-Kuckuck, Ann. Rev. Nucl. Sci. 16, 183 (1963).

2. S. Frautschi, Nuovo Cimento 12A, 133 (1972).

3. K. A. Jenkins et al., Phys. Rev. Letters 40,425 (1978).

\section{Figure Caption}

Fig. 1 Differential cross sections at constant $t$. The top number by each set of data points gives $-t$ in $\mathrm{Gel} / \mathrm{c}^{2}$. The bottom number, if present, is a scale factor by which do/dt has been multiplied for presentation. Cross sections have been averaged over t-ranges of approximately $\pm 4 \%$. 


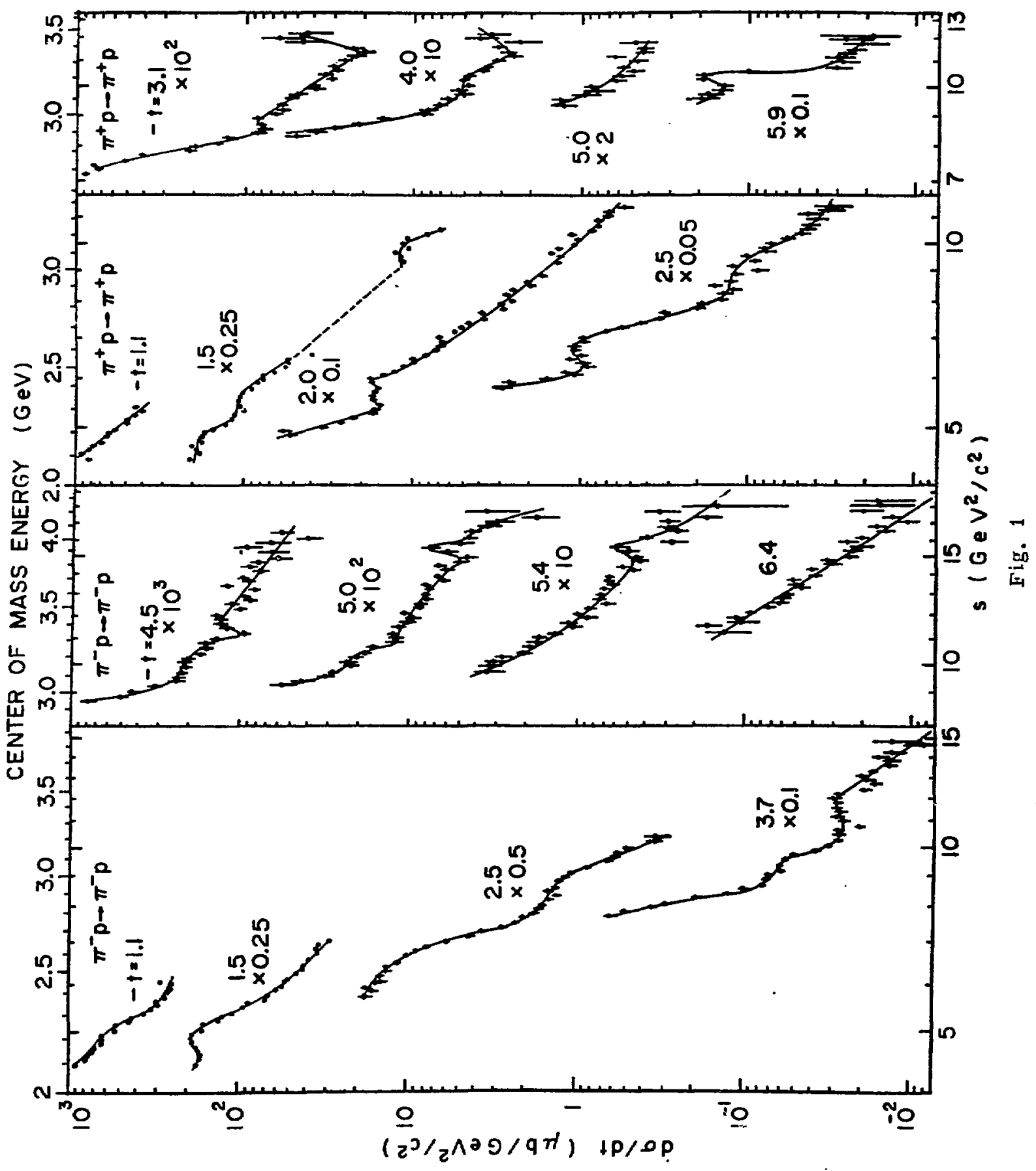

